\title{
Métodos Geoelétricos aplicados na caracterização hídrica de barragens de terra: caso da barragem de Santa Selena - BA.
}

\author{
Schibelscky,Mariana L. N. O. S., UFBA; Lima, Olivar A. L., UFBA; Maly, Mascimiliano S., USP.
}

Copyright 2018, SBGf - Sociedade Brasileira de Geofísica

Este texto foi preparado para a apresentação no VIII Simpósio Brasileiro de Geofísica Salinópolis, 18 a 20 de setembro de 2018. Seu conteúdo foi revisado pelo Comitê Técnico do VIII SimBGf, mas não necessariamente representa a opinião da SBGf ou Técnico do VIII SimBGf, mas não necessariamente representa a opinião da SBGf ou propósitos comerciais sem prévia autorização da SBGf.

\section{Resumo}

O potencial dos métodos geofísicos elétricos na caracterização hídrica de barragens de terra foi demonstrado no estudo de caso da Barragem de Santa Helena, a leste da Bahia, no município de Camaçari. O método da Eletrorresistividade contribuiu na indicação de zonas de saturação anômala à jusante do filtro da barragem. Sua integração com o método de Polarização Induzida é imprescindível para se resolver as ambiguidades de anomalias condutoras, se estas são de natureza hídrica ou composicional. O método do Potencial Espontâneofoi usado para o reconhecimento de fluxos anômalos no maciço da barragem. A facilidade de integração dos resultados dos três métodos permitiu uma avaliação preliminar das condições hidrológicas da barragem, indicando uma possível zona de infiltração na região adjacente ao vertedouro.

\section{Introdução}

A caracterização hidráulica de uma barragem de terra é de total relevância e prioridade nas rotinas de monitoramento dessas estruturas. Para tanto, a aplicação dos métodos geofísicos elétricos pode em muito contribuir na detecção de percolações anômalas no maciço, fundação e ombreiras das barragens de terra, com as vantagens de serem métodos não invasivos e de poderem ser realizados em um mesmo levantamento para poder, dessa maneira, integrar seus resultados enriquecendo a interpretação e eliminando as ambiguidades inerentes de cada método.

Os métodos geoelétricos Eletrorresistividade (ER), Polarização Induzida (IP) e Potencial Espontâneo (SP) foram aplicados na barragem de terra de Santa Helena (BSH), localizada a leste da Bahia e que desempenha um papel importante no abastecimento de água da região metropolitana de Salvador. O método ER oferece uma imagem em subsuperfície da propriedade física resistividade elétrica e, a partir dela, infere-se sobre a natureza da condução elétrica em subsuperfície que pode estar relacionada ao grau de saturação do material da barragem bem como a variações composicionais ao longo do maciço, ombreiras e fundação da mesma. O método IP, por sua vez, fornece um ótimo indicativo de variações em teor de argila do material, pois baseia-se no fenômeno de polarização de membrana, efeito tal observado em meios porosos saturados ou semisaturados com algum conteúdo em argila. Além destes métodos de fonte artificial, o método SP, indica a presença e direção de fluxos de água que possam estar ocorrendo no maciço da barragem (Ward, 1990).

Assim, de acordo com a potencialidade de cada método, foi possível caracterizar a barragem de Santa Helena em termos de saturação de água ao longo do corpo da barragem, onde uma percolação anômala de água foi detectada na região adjacente ao lado direito do vertedouro.

\section{Metodologia}

Os métodos elétricos baseiam-se na injeção de uma corrente elétrica de intensidade conhecida na subsuperfície e na medida da diferença de potencial em superfície usando eletrodos. Os fundamentos físicos que embasam este procedimento é a Lei de Ohm na forma vetorial, a qual descreve o fluxo de corrente no interior de um meio condutor, e o princípio de conservação da carga elétrica sob condição estacionária. Através destes fundamentos, chega-se a Equação de Poisson na forma

$$
\nabla^{2} v=\frac{1}{\sigma} I \delta\left(x-x_{f}\right) \delta\left(y-y_{f}\right) \delta\left(z-z_{f}\right)
$$

onde $v$ é o potencial elétrico, $\sigma$ é a condutividade elétrica dada em $\mathrm{S} / \mathrm{m}$, I é uma fonte de corrente pontual, $\delta$ é a função Delta de Dirac e $\left(x_{f}, y_{f}, z_{f}\right)$ são as coordenadas da posição da fonte.

O método da eletrorresistividade fundamenta-se na determinação da distribuição do potencial elétrico associado às fontes pontuais de correntes elétricas contínuas ou de baixas frequências, localizadas na superfície terrestre ou em profundidades no interior de poços. Dessas distribuições de potenciais pode-se inferir a estrutura geológica da subsuperfície em termos da geometria e das resistividades elétricas de suas diferentes regiões (Ward, 1990). As medidas de potencial elétrico permitem inferir a distribuição da resistividade aparente dos materiais em subsuperfície através da relação

$$
\rho=\frac{\Delta v}{I} K
$$

sendo $\mathrm{K}$ o fator geométrico do arranjo de eletrodos dado por

$$
K=2 \pi\left(\frac{1}{A M}-\frac{1}{B M}-\frac{1}{A N}+\frac{1}{B N}\right),
$$

onde A e B são os eletrodos de corrente e $\mathrm{M}$ e $\mathrm{N}$ os eletrodos de potencial.

Variações da propriedade resistividade aparente podem estar associadas a diversos parâmetros geológicos e hidrológicos. No caso do estudo de barragens, a 
expectativa é inferir sobre regiões de vazamentos e zonas de fissuras.

O fenômeno de polarização induzida basicamente, se relaciona ao transporte de carga elétrica em interfaces onde ocorre uma modificação na forma de condução da corrente elétrica no meio. É possível distinguir duas origens para a polarização induzida: a polarização metálica ou eletrônica, e a polarização de membrana, das quais a última fundamenta a aplicação do método em barragens de terra. A polarização de membrana ocorre devido à presença de minerais de argila na matriz rochosa. Na vizinhança da superfície da argila ocorre uma nuvem difusa de cátions, conhecida como camada dupla. Quando se aplica um potencial elétrico, as cargas positivas atravessam facilmente a nuvem catiônica, enquanto que os íons negativos se acumulam. Assim, a dupla camada exerce o papel de membrana seletiva de íons (Ward, 1990). Eliminado o potencial, todas as cargas voltam para a posição de equilíbrio. O método IP no domínio do tempo baseia-se nas medidas discretas do decaimento da voltagem no tempo após a corrente ser desligada. O parâmetro medido é chamado de cargabilidade aparente $m$, dada em $\mathrm{mV} . \mathrm{s} / \mathrm{V}$ e definida pela razão entre o pico primário de tensão quando a fonte está ligada, $v_{p}$, e o pico secundário, $v(t)$, obtido imediatamente após a interrupção da corrente. A razão entre as tensões, em um intervalo $\Delta t=t_{2}-t_{1}$ é expressa a seguir

$$
m=\frac{1}{v_{p}} \int_{t_{1}}^{t_{2}} v(t) d t
$$

O método do potencial espontâneo (SP) baseia-se na medida do potencial elétrico na superfície devido à existência de correntes naturais na subsuperfície (Corwin, 1990). A formação destas correntes naturais no interior das rochas deve-se a diversos fatores dentre os quais o mais relevante para a caracterização hidrológica de barragens de terra é o fluxo de fluidos e íons. A este tipo de fonte natural chama-se potencial de eletrofiltração, potencial de fluxo ou ainda potencial eletrocinético. O potencial de fluxo ocorre quando uma solução de resistividade $\rho$ e viscosidade $\eta$ é forçada através de um meio poroso capilar. As paredes dos poros por onde a água passa retém, em geral, cargas negativas compensadas por contra-íons em duplas camadas elétricas. No decorrer do fluxo hidráulico, os íons positivos carreados pela água, concentram-se no final dos poros. A diferença de potencial entre os extremos dos poros é dada por

$$
E_{k}=\frac{\phi \Delta P \varepsilon \rho}{4 \pi \eta}
$$

onde $\phi$ é o potencial de adsorção (potencial da dupla camada), $\Delta P$ é a diferença de pressão, e $\varepsilon$ é a constante dielétrica da solução. Devido a esta tendência da água em fluxo carrear preferencialmente os cátions, é possível realizar a caracterização hidrológica do meio, pois a direção do fluxo de água será do potencial negativo para o potencial positivo.

\section{Barragem de Santa Helena}

A barragem de Santa Helena localiza-se no município de Camaçari, Bahia, e represa o rio Jacuípe a $35 \mathrm{~km}$ de sua desembocadura. Por meio dela se faz o abastecimento de água de toda região, incluindo a Região Metropolitana de Salvador. A Bacia do Rio Jacuípe é caracterizada por uma topografia levemente ondulada e o contexto geológico em que esta se insere é da Bacia Sedimentar do Recôncavo, com predomínio das rochas sedimentares da Formação São Sebastião composta por arenitos, siltitos e folhelhos.

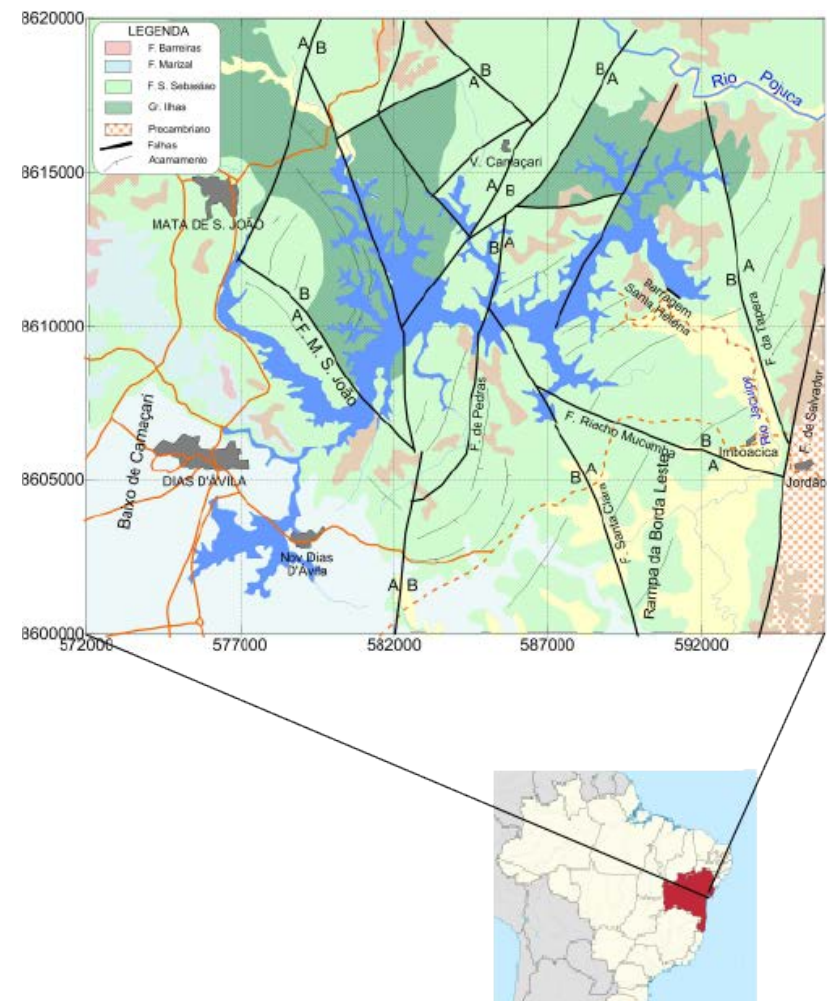

Figura 1 - Mapa geológico da região do entorno da Barragem de Santa Helena.

UTM: zona 24.

A Figura 1 mostra um mapa geológico da região do entorno da barragem de Santa Helena. Nela, destaca-se a grande extensão de ocorrência da Formação São Sebastião, sobreposta à sedimentos do Grupo Ilhas e recoberta por manchas descontínuas da Formação Barreiras. O Grupo Ilhas é composto por formações predominantemente deltáicas (Formações Pojuca, Marfim e Taquipe). A Formação São Sebastião é caracterizada pelo predomínio de fácies fluvial característica da fase final de rifteamento, durante o Cretáceo, andar Buracica a Jiquiá (Troccoli, 2015; Silva et al. 2007). Já a Formação Barreiras é de deposição mais recente, Neógeno, no contexto de sistemas deposicionais fluviais da fase pósrifte. Destaca-se também a grande quantidade de falhas normais, com orientações gerais SSW-NNE, bem como 
falhas de alívio (SE-NW) que fazem parte da Zona de Falha Mata-Catu.

A Embasa é a atual operadora desta barragem. Seu maciço é composto por terra compactada de seção homogênea, com comprimento de $290 \mathrm{~m}$ pela crista e altura máxima de $23 \mathrm{~m}$ até a fundação, e capacidade de acumulação de $240,6 \times 10^{6} \mathrm{~m}^{3}$, com um espelho d'água de $40,3 \mathrm{~km}^{2}$. Para o sistema de drenagem interno foi utilizado um filtro vertical de areia tipo "chaminé" e um tapete drenante horizontal, até o limite de jusante do aterro. Um fator relevante neste estudo de caso é que esta barragem sofreu rompimento por galgamento em 1985 e foi reconstruída no ano 2000 com algumas modificações em contrapartida ao projeto inicial da mesma. Segundo Amorim (2008), dentre as modificações feitas, destacam-se o comprimento do coroamento que passou de 260 para $290 \mathrm{~m}$; a largura do vertedor que passou a ser de $26 \mathrm{~m}$ e com três comportas, a fundação do novo vertedor de concreto compactado com rolo (CCR), com execução até o topo da rocha e posterior enchimento com CCR, visando proporcionar maior estabilidade, uma vez que antes era composta por aterro argiloso compactado, colchão de areia e arenito.

\section{Levantamentos Geoelétricos na Barragem de Santa Helena}

Os dados utilizados foram obtidos em 2015, com o eletrorresistivímetro Syscal Pro fabricado pela Iris Instruments. A Figura 2 a seguir mostra a disposição das linhas na barragem, sendo 7 linhas paralelas à crista da barragem e duas transversais sobre as ombreiras. Há dados de eletrorresistividade e potencial espontâneo em todas as linhas. Os dados de polarização induzida estão presentes das linhas 3 à 9. Para os dados de ER e IP o arranjo adotado foi o Dipolo-Dipolo, com espaçamento de $10 \mathrm{~m}$.

A inversão 2-D dos dados foi realizada com o software RES2DINV (Geotomo Software, 2004). Este programa baseia-se no método mínimos quadrados com vínculos de suavização restringida smoothness-constrained leastsquare inversion.

\section{Interpretação dos dados}

\section{Linhas paralelas ao eixo da barragem}

A Linha 7 localiza-se sobre a crista da barragem, à montante de seu filtro. De maneira geral, a porção sudeste da linha apresenta mais baixos valores de resistividade, em contraste com a porção centralnoroeste da seção de ER e foi denotada como anomalia 1 (Figura 2). Este baixo resistivo, com valores de até 44 ohm.m, encontra-se na região da barragem adjacente ao vertedouro, região crítica para o surgimento de pequenos fissuramentos acarretando uma maior saturação. Ademais, a localização desta anomalia é descrita na literatura, como integrante da brecha que se formou quando a barragem se rompeu em 1985 (Amorim, 2008).
Por esta descrição, a barragem ficou intacta até os 160 $\mathrm{m}$, e a linha 7 chega até os $175 \mathrm{~m}$ da ombreira direita.

Sabe-se que uma anomalia condutiva nas seções de eletrorresistividade sofre ambiguidade pela possibilidade de duas situações que geram uma maior condução elétrica: o aumento de eletrólitos em circulação, que se traduz em maior saturação; ou um aumento no teor de argila do material que constitui a barragem. Esta ambiguidade pode ser resolvida pela seção de cargabilidade, pois devido ao fenômeno de polarização de membrana, anomalias positivas desta propriedade são observadas em regiões com maior teor de argila.

Atribui-se a anomalia de alta resistividade, à distância de $120 \mathrm{~m}$ da linha 7, abaixo da cota de $10 \mathrm{~m}$ ao canal de desvio usado durante a reconstrução da barragem, que possuía revestimento de concreto (Figura 2).

Estas anomalias indicativas de alta saturação em água foram identificadas nas demais seções de ER à jusante do filtro tipo chaminé da BSH, e podem ser observadas na Figura 5. As linhas 1, 2 e 3 encontram-se à jusante do filtro tipo chaminé da barragem. Na Linha 1 percebe-se a continuidade lateral das anomalia 1 e 2 exibidas na Linha 7, porém ambas com uma geometria ligeiramente diferentes (Figura 5-B). A anomalia 1 apresenta valores de resistividade um pouco mais altos no extremo sudeste da seção, do que na seção de ER da linha 7. Porém, a região de mais baixos valores da anomalia é maior do que na seção de ER da linha 7, demonstrando que está ocorrendo uma percolação de água anômala à jusante do filtro da barragem. A Linha 2, $8 \mathrm{~m}$ à jusante da Linha 1 , apresenta também anomalias de baixa resistividade com geometrias ligeiramente diferentes das seções de ER das linhas 7 e 1 (Figura 5-C) Nota-se um espraiamento da anomalia 1, demonstrando que a saturação do meio nesta região é menor do que nas linhas 7 e 1 . A anomalia 2 encontra-se com geometria ligeiramente diferente e, mantendo-se a hipótese de que os baixos de resistividades são devidos à maior saturação do material, um pico de saturação parece ocorrer na anomalia de maneira concêntrica e a sudeste, a $130 \mathrm{~m}$ de distância e abaixo da cota de $10 \mathrm{~m}$, com valores de resistividade da ordem de 30 ohm.m. Uma infiltração pela fundação da barragem, que é argilosa, ou uma infiltração advinda do reservatório são uma possibilidade para a ocorrência destes picos de saturação. Em todo caso, os resultados sugerem que filtro tipo chaminé e o tapete drenante horizontal não estão eficientes no direcionamento do fluxo de água percolante no corpo da barragem. Na Linha 3 a anomalia 1 já encontra-se bem espalhada e sem picos de baixa resistividade como os das linhas 7, 1 e 2 (Figura 5-D). Infere-se que a percolação anômala na lateral do vertedouro não alcança regiões muito à jusante do barramento. A anomalia 2 está descaracterizada, porém com um pico de alta condutividade na região mais profunda da seção imageada, a cerca de $45 \mathrm{~m}$ de distância e abaixo da cota $0 \mathrm{~m}$. A linha 3 possui dado de IP exibido na Figura 3, onde pode-se observar duas anomalias, 1 e 2, de alta cargabilidade atribuídas a uma maior influência do conteúdo em argila da fundação nesta linha, haja vista que esta se encontra na cota mais baixa 


\section{Linha 7}

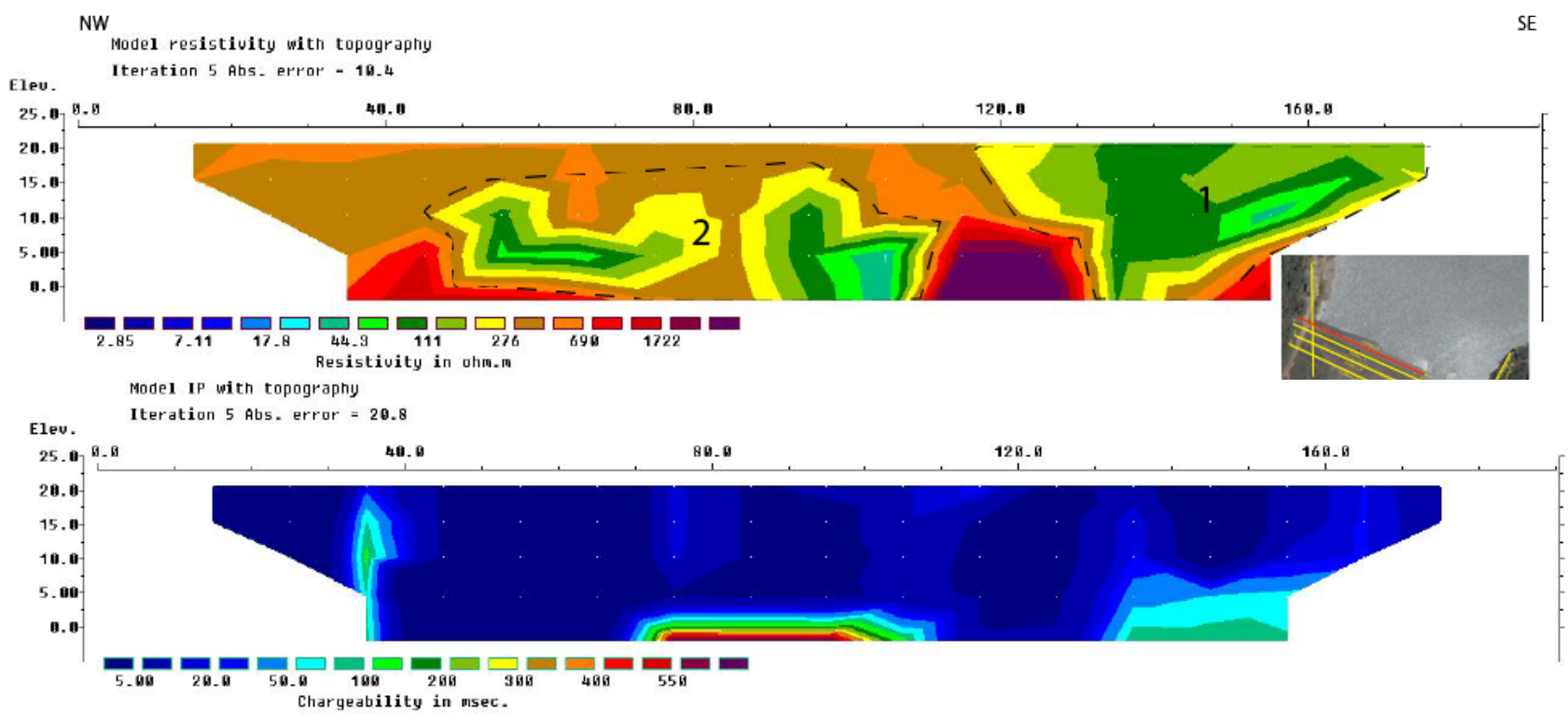

Figura 2 - Linha 7, na crista da barragem, à montante. Topo: dado de ER. Base: dado de IP.

dos dados adquiridos e, logo, imageia regiões mais profundas.

As linhas 8, 5 e 6 encontram-se entre o vertedouro e a ombreira esquerda da barragem, estando a linha 8 à montante do filtro e as linhas 5 e 6 à jusante do mesmo (Figura 5-E, 5-F, 5-G). A linha 8, na crista de barragem à montante, apresenta valores de resistividade mais baixos do que as linhas 5 e 6 , o que se espera, pois esta encontra-se limitando o reservatório de água e, logo, imageia uma região mais saturada (Figura 5-E). As linhas 5 e 6 em geral apresentam altos valores de resistividade, o que demonstra que deste lado do vertedouro, não está havendo uma percolação anômala à jusante do filtro da barragem.

\section{Linhas nas ombreiras}

A Linha 4 é orientada na direção quase N-S sobre a ombreira direita da barragem. $O$ dado de ER invertido apresenta algumas anomalias muito resistivas próximas à superfície que refletem a zona não-saturada da Formação São Sebastião, permitindo-se inferir o limite marcado como a posição do nível estático do aquífero . As regiões mais profundas da seção de ER desta linha exibem um pacote de material mais homogêneo a norte, essencialmente na ombreira direita, gradando para um material menos resistivo ao sul, onde a linha cruza o maciço da barragem e as demais linhas de aquisição longitudinais. Atribuiu-se a estas anomalias de relativa mais baixa resistividade a uma maior saturação da região, como visto nas linhas 7, 1, 2 e 3 (Figura 5).

O dado de IP da Linha 4 apresenta-se sem anomalias de cargabilidade ao longo da seção imageada, o que demostra pouca variação de composição entre o material da barragem e o material da ombreira direita, hipótese tal corroborada pela literatura da construção da $\mathrm{BSH}$, pois em relatório técnico, cita-se que a principal

\section{Linha 3}

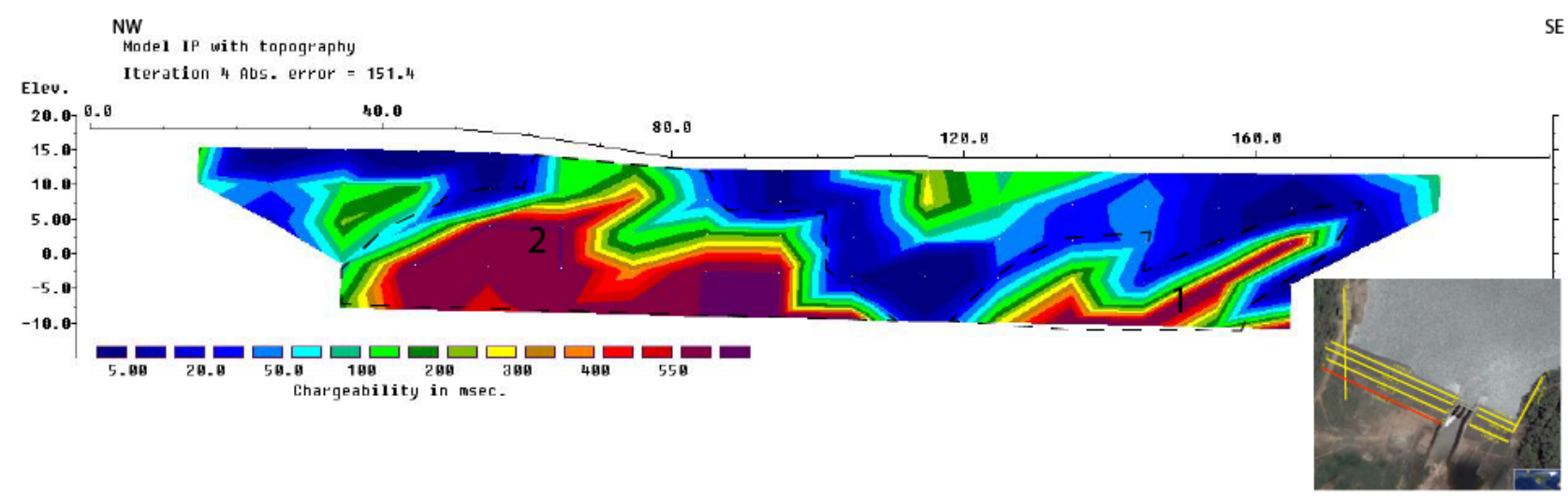

Figura 3 - Dado de IP linha 3 - linha mais à jusante do levantamento. 
área de empréstimo utilizada para se obter o material para a construção da barragem, estava na ombreira direita, a apenas $700 \mathrm{~m}$ do eixo da BSH (GEOTÉCNICA,1975). Ademais, a literatura sobre o rompimento da $\mathrm{BSH}$ deixa bem claro que esta ombreira ficou intacta cerca de $160 \mathrm{~m}$. Sendo assim, não se esperam mudanças bruscas de material entre a ombreira direita e o maciço do barramento.

A Linha 9 está orientada na direção NE-SW aproximadamente e encontra-se sobre a ombreira esquerda da barragem. Nesta região da ombreira, a resposta elétrica do método ER exibe um extenso pacote

homogêneo, com uma maior saturação no extremo NE da linha, onde apresenta os maios baixos valores de resistividade. De acordo com profissionais atuantes na área, em consulta pessoal, esta ombreira está passando por processos erosivos que podem estar associados a esta baixa resistividade. Na porção sudoeste da linha, vemos uma anomalia de alta resistividade, atribuída a influência de rochas presentes nesta ombreira e relatada na literatura (Amorim, 2007).

\section{Potencial Espontâneo}

O dado de SP foi adquirido com o arranjo tipo gradiente e está exibido na Figura 4 sobreposto à topografia da barragem. Observa-se os maiores valores de SP na região circunvizinha ao vertedouro, demonstrando a presença de um fluxo anômalo de percolação de água nesta região, o que confirma o alto teor de saturação deste local indicado pelos dados de ER das linhas 7, 1, 2 e 3 analisados anteriormente.

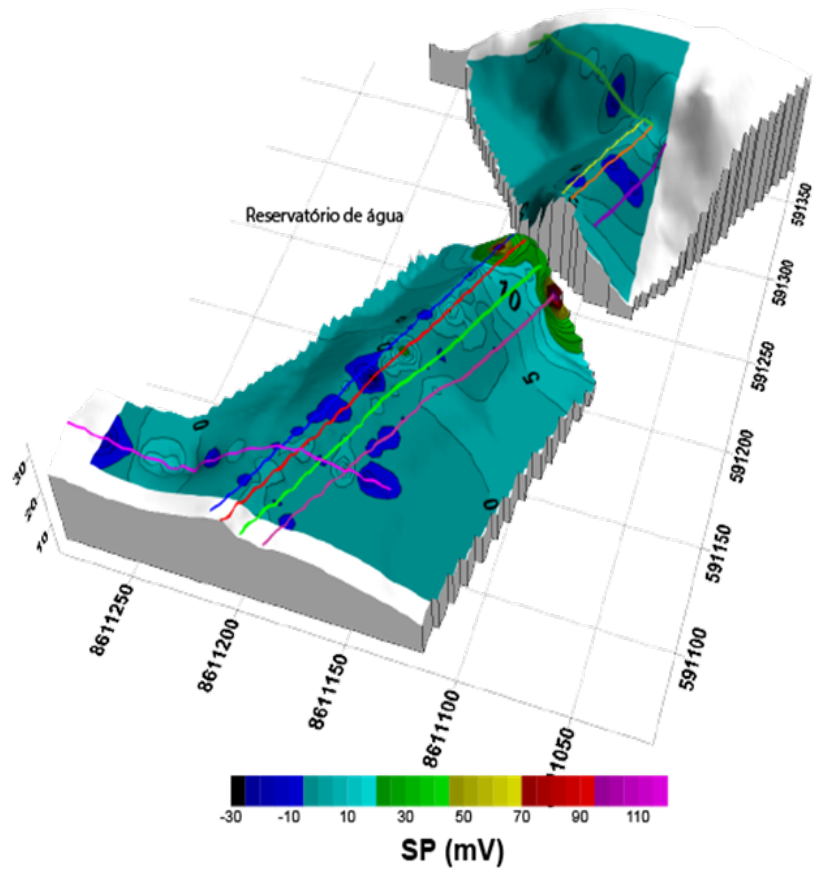

\section{Conclusões}

A integração dos resultados dos métodos geoelétricos é muito proveitosa para eliminar as ambiguidades de cada método e enriquecer a interpretação. A análise preliminar dos dados adquiridos na Barragem de Santa Helena, mesmo que bidimensional, permitiu detectar regiões de alta saturação e fluxos de percolação anômala de água, localizados principalmente na região adjacente ao vertedouro voltado para a ombreira direita da barragem. Esta infiltração no maciço vem majoritariamente do reservatório à montante e diminui para jusante dentro do maciço.

Diante do exposto, fazem-se necessárias recomendações de estudos de detalhe com métodos diretos nesta região, bem como a realização de novos levantamentos geofísicos em regiões mais à jusante da barragem, para monitorar a extensão desta infiltração.

\section{Agradecimentos}

Agradecemos ao Prof. Eng. Luis Edmundo Prado de Campos Prado pelas discussões e contribuições.

\section{Referências}

AMORIM, J. L. R. 2007. Barragem de Santa Helena. Relatório Técnico. Salvador: EMBASA. 73 p.

CORWIN, R. F. 1990. The Self-Potential Method for Environmental and Engineering Applications, In: Geotechnical and Environmental Geophysics, Ward, S. (Ed) v. 1. Tusa-Oklahoma: Society of Exploration Geophysics, p. 127-145.

SILVA, O. B.; CAIXETA, J. M.; MILHOMEM, P. S. e KOSIN, M. D. 2007 Bacia do Recôncavo. Boletim de Geociências. Petrobrás, v.15, p. 423-431.

TROCCOLI, E. 2015. Sismoestratigrafia em Bacias Rifte e Análise de Atributos Sísmicos e Filtros na Interpretação de Dados 2D e 3D na Bacia do Recôncavo, Dissertação de Mestrado, Programa de Pós-Graduação em Geofísica, Universidade Federal da Bahia, 88p.

WARD, S. 1990. Resistivity and Induced Polarization Methods", In: Geotechnical and Environmental Geophysics, Ward, S. (Ed) v. 1. Tulsa-Oklahoma: Society of Exploration Geophysics, p. 147-188.

Figura 4 - Dado de SP sobre a geometria da barragem. Coordenadas UTM: zona 24. 

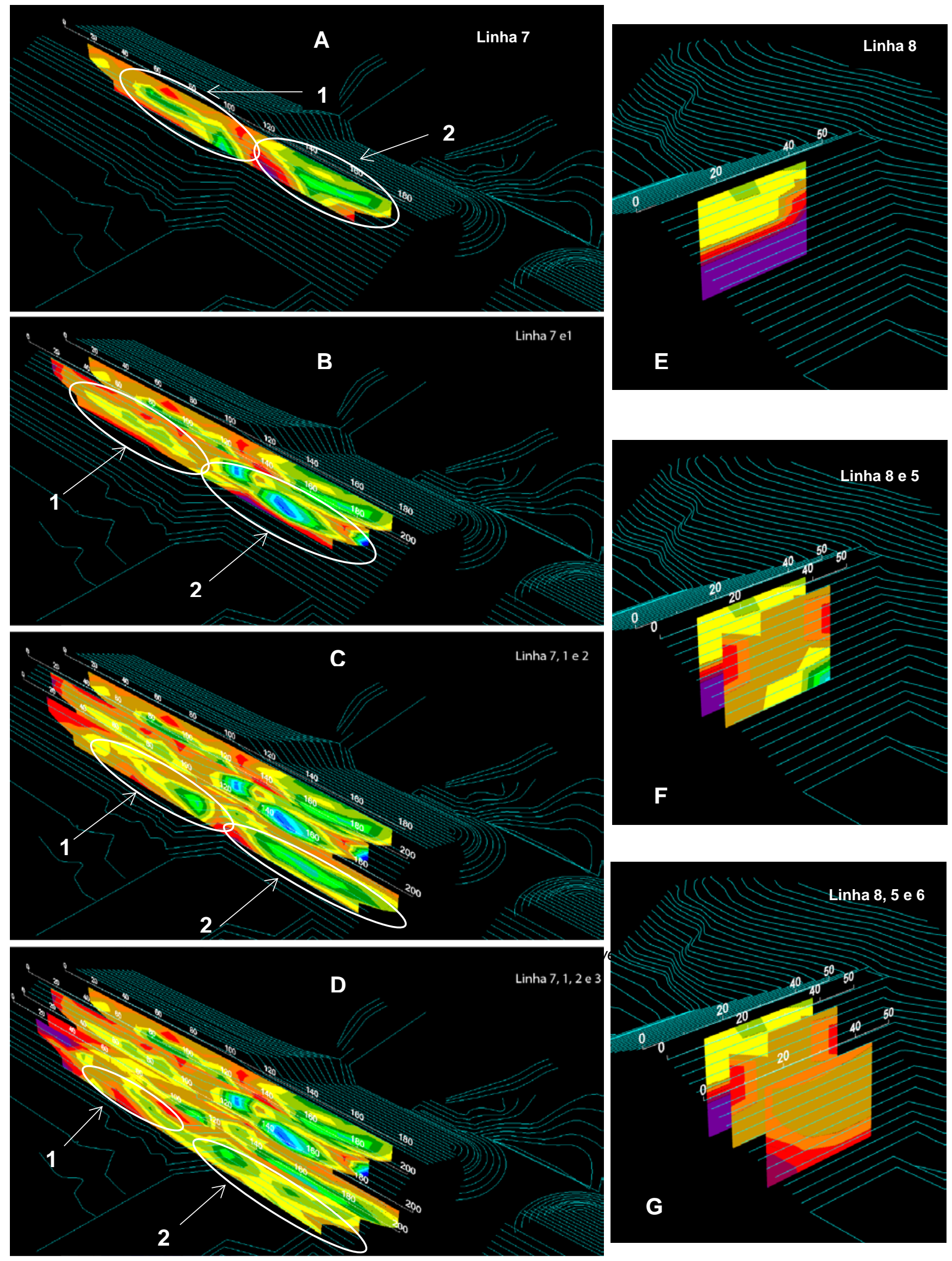

Figura 5 - Linhas de ER longitudinais ao eixo da barragem. A, B, C, D: linhas à direita do vertedouro. E, F e G: linhas à esquerda do vertedouro. 